\title{
Research on the Development of China University Library Alliances
}

\author{
Lei Yi \\ Library, Beijing University of Chemical Technology, Beijing, China \\ Email:kant20042000@163.com
}

How to cite this paper: Yi, L. (2020) Research on the Development of China University Library Alliances. Open Access Library Journal, 7: e6688.

https://doi.org/10.4236/oalib.1106688

Received: August 4, 2020

Accepted: August 18, 2020

Published: August 21, 2020

Copyright $\odot 2020$ by author(s) and Open Access Library Inc.

This work is licensed under the Creative Commons Attribution International License (CC BY 4.0).

http://creativecommons.org/licenses/by/4.0/

\section{(c) (i) Open Access}

\begin{abstract}
With the continuous development of information technology, the university library alliances (ULA) have gradually changed from "entity alliance" in the last century to the "entity body combined with digitizing brain" in the present. In the near future, smart libraries (SL) and cloud service platforms (CSP) will be the real protagonists of the library alliances. In this process, the use of artificial intelligence (AI) and cloud computing (CC) technology will become an important trend. The continuous development of China University Library Alliance (CULA) is the result of using emerging information technology to continuously satisfying the needs of readers. In the era of big data, the analysis of mass document data will become a new topic in the development of ULA, and its service focuses will gradually be transferred from traditional business to document data. With the development of AI and CC, focusing on the intelligent, specialization and individuality of the service is the inevitable trend. This article mainly adopts the research method of comparative library science and historical analysis to explain the important characteristics of different development stages of CULA, to analyze the problems of "entity alliances" and "hybrid alliances", and then to explain why cloud libraries of big data (BD) and smart libraries will be the mainstream of CULA.
\end{abstract}

\section{Subject Areas}

Library, Intelligence and Philology

\section{Keywords}

ULA, Entity Alliance, Hybrid Alliance, Virtual Alliance, Big Data, AI

\section{Introduction}

Library Alliance (LA) refers to the cooperative body established between libra- 
ries, which has the functions of resource sharing and co-construction, interlibrary loan, joint catalog, personnel training, consultation and cooperation, etc. [1]. The main function of LA is the sharing of literature resources. In fact, no library has all the resources, so it is a good idea to form alliances to obtain the resources they need. The needs of readers, the development of information technology, the mutual benefit and sharing of literature resources, and the reduction of operating costs and the improvement of service level are the important reasons for the continuous formation of alliances among university libraries (UL) [2]. It is just the emerging information technology that fundamentally determines the development direction and organizational form of the university library alliance. If we investigate the development of the ULA in China since the past 30 years, we will find that the year 2000 is a particularly important year, because before that, the "alliance" was mainly based on "entity", and its "virtual body" component was very small (the "entity" here mainly refers to the "paper literature", "physical space" and other physical properties of university library). Since 2000 later, the Internet developed rapidly in China. It was also at this time people began to emphasize the networking and informationization of libraries. Later then, information technology has played an increasingly important role in the development, transformation and upgrading of "alliance" [3]. In this process, it has become a main trend of the development of the ULA. The ULA have also changed from the "entity alliance" (EA) in the last century to the current "entity combined with virtual body" alliance. As we enter the era of big data, a large amount of literature information, a large amount of video and audio data, various interactive information between readers and the library, and a wide range of freely available online open resources require us to use big data (BD) tools for processing to deal with. The $\mathrm{BD}$ is usually used to describe a large amount of unstructured data and semi-structured data created by a society, which is a data collection that is so large in terms of data acquisition, storage, management, and analysis that it far exceeds the capabilities of traditional database software tools. It has massive data scale, fast data flow, and diverse data types, etc. In the feature, with the advent of the era of $\mathrm{BD}$, the $\mathrm{BD}$ analysis has also attracted more and more attention. The BD analysis is often associated with cloud computing (CC). Technically, the relationship between $\mathrm{BD}$ and $\mathrm{CC}$ is as inseparable as the front and back of a coin. BD cannot be processed by a single computer, and a distributed architecture must be adopted. Its characteristic lies in the distributed data mining of massive data. But it must rely on the distributed processing of cloud computing, distributed database and cloud storage, and virtualization technology. Processing BD requires special technologies, which include massively parallel processing databases, data mining, distributed file systems, distributed databases, CC platforms, the Internet, and scalable storage systems. In recent years, BD analysis has also attracted the attention of academic libraries, and scholars have begun to explore the possibility of integrating BD analysis into the construction of the ULA [4]. The mining and utilization of BD has become a 
subject that the library community must face. With the continuous expansion of the alliance scale and the deepening of cooperation, in the era of big data (BD) and AI, the development of ULA will inevitably tend to the pattern of "virtual body alliance". One of the main reasons why UL are willing to participate in various LA is that no library can have all the resources. The original intention of cooperation between libraries is to realize the sharing of literature resources to satisfy the needs of readers. Information technology provides tools for resource sharing between UL and reduces the cost of sharing resources. How does the development of information technology cause continuous changes in the organization of ULA is certainly one of the core issues that this article focuses on.

\section{The Main Types of CULA}

Before the birth of information technology such as the Internet, although there were also ULA, its scale and influence are simply not the same as today's ULA. In essence, it is the emerging information technology that determines the size of the ULA and the depth and breadth of cooperation between them. We have to say that emerging information technology (IT) has played a key role in the development of CULA. Without IT, the construction of large ULA and super ULA would not be realized. Therefore, emerging IT is the real incentive for the reform of library organization, and it is also very necessary to better satisfy the needs of readers. According to the actual situation of development in recent decades, the CULA can be divided into entity alliance (EA), hybrid alliance (HA) and virtual entity (VE) according to its network and digitization degree. EA is mainly a product of the pre-Internet era, and it has been gradually eliminated. HA is the product of the Internet and the digital age. It is the most popular form of ULA organization in the past two decades. Due to the continuous development of the Internet, it is in these two decades that Chinese academic libraries have rapidly completed networking and digitization. Now the mainstream alliance is the mixed alliance of "entity plus virtual", which is also a reflection of "Internet plus" in the library community. Although HA will be popular for a period of time, it is VE that can really represent it. In the era of big data, artificial intelligence and cloud computing are the protagonists of technology and the real soul of the future development of ULA.

\subsection{Entity Alliance}

In the last century, the organizational form of CULA is characterized by EA. Due to the underdevelopment of information technology and network technology, the ULA were very small at that time. Without the support of advanced information technology, the ULA could only be a cooperative relationship between several adjacent university libraries. For example, the mutual borrowing business carried out earlier by Tsinghua University Library and Peking University Library belongs to the alliance cooperation between the two entity libraries in essence. Of course, this alliance relationship can also be constructed among multiple 
physical libraries, but the scale of their cooperation was not very large, the scope of business was also very narrow, and even there were not many business contacts. The EA mostly occurred in the pre-Internet era. Relying on geographic relationships between university libraries, some paper-based collections were shared. This type of cooperation is often limited by geographical and technological constraints, and often lacks cooperation depth. After entering this century, this alliance method has not disappeared. In 2002, 11 university libraries including Beijing University of Posts and Telecommunications Library, Beijing Normal University Library, Renmin University Library of China, etc., jointly initiated the establishment of the "Beijing North Third Ring Road University Library Consortium", which is a typical representative of this kind of alliance (in 2006, the consortium was renamed "Beijing University Library Consortium (BULC)", and the number of staff libraries has been expanded to 39). The main cooperation method of the alliance is to distribute book borrowing cards among member libraries to satisfy the willingness of some readers to borrow books in libraries from other universities. According to the rules for the formation of the alliance, each member library can obtain more than 10 borrowing cards from other member libraries of universities, and readers can borrow 3 books with this card to the corresponding foreign university library [5]. Due to the lack of follow-up of network technology, this alliance service method can only meet the needs of a few readers. At present, this type of alliance is no longer the mainstream way of cooperation in the academic library community. Now the BULC's business has basically been replaced by the more advanced Beijing Academic Library \& Information System (BALIS). BALIS is currently the largest regional library consortium in Beijing, which has a document sharing system and its document resources are more abundant. Basically, the BULC member libraries have signed up to join BALIS. Therefore, in this case, the BULC has lost the meaning of existence. In the EA era, each university library is still an island of information, and the barriers to resource sharing cannot be broken. The cooperation between various university libraries is a very limited cooperation, and personnel exchanges and information transmission are extremely limited. The earth is restricted. Therefore, it is inevitable that EA will be eliminated by history.

\subsection{Hybrid Alliance}

At present, the hybrid alliance ("entity combined with virtual body") is more popular in China. This kind of alliance often relies on mature system platform and convenient network environment to provide readers with original text transmission, interlibrary loan, information consultation and other services. BALIS is a typical representative of this kind of alliance. Now, BALIS has 90 member libraries, and its rapid growth confirms the comparative advantages of HA-low cost, quick effect, flexible communication and smooth operation, which can not only quickly realize the sharing of resources, but also save a lot of organizational costs [1]. It can be said that this form adapts to the development 
trend of ULA in China.

Information technology plays a vital role in promoting the rapid development of HA. The rapid development of network technology has greatly reduced the cost of document information transmission, and also has provided an indispensable tool for the in-depth development of university libraries alliances. In particular, the "sharing system" (SS) built on the basis of network tools is an indispensable infrastructure for the integration of resources of the university library alliance [6]. It can be said that if there is no convenient SS, the alliance will not be able to conduct business efficiently. Therefore, all alliances attach great importance to the development or purchase of SS. The Tianjin University Library Consortium started by relying on the joint construction of the automated management system of member libraries [6]. At present, their circulation, acquisition and editing staff share a system platform. Another important representative of the HA is the digital library or the network library. The "Beijing University Network Library" was opened in 2002 and currently has 41 member libraries [6]. After more than ten years of development and construction, the alliance has played a significant role in sharing databases, providing query, retrieval, and document resource construction.

In the HA era, information islands have been gradually broken, and resource sharing between SS university libraries has been greatly improved. This is HA's greatest contribution. It can be said that HA has solved the problem of networked links between Chinese academic libraries. The main problem with HA is that it is still centered on "document resources" rather than readers. In essence, it has not completely broken the imagination of information islands in the library world. Therefore, managing it is a huge progress in China's academic libraries, but it will also be eliminated by history in the near future, especially entering the era of $\mathrm{BD}$ and artificial intelligence, which will accelerate this process. Judging from the existing information technologies, HA has fallen behind.

\section{The Cloud Library (CL) and Smart Library (SL)}

With the development of technologies such as the Internet, social networks, and smart mobile devices, data has exploded, and data structure types are also complex and diverse. Big data fills every corner. Various characteristics indicate the arrival of the BD era. In the era of big data (EBD), it is certain that the construction of university library alliances must have $\mathrm{BD}$ mind. The $\mathrm{BD}$ thinking is not just thinking about how to store, process, and analyze massive amounts of data, but more importantly, look at readers from a new perspective. From a macro perspective, the use of $\mathrm{BD}$ technology to integrate different types of literature data can promptly grasp readers' reading trends, document download frequency, database usage, and conduct in-depth analysis based on readers' interest and preferences in downloading documents to predict the literature information that may be most needed, and provide it to the manager of the library consortium as a reference for the construction of literature resources. From a micro perspec- 
tive, the reader behavior prediction helps the management and service entities of the library consortium to keep abreast of readers' dynamics and improve our management and services. In the first two decades, we paid more attention to the networking and digitization of the ULA, but with the completion of the network and digitization construction of the CULA, we are now more concerning about how to use cloud computing (CC) and artificial intelligence (AI) technology to handle massive amounts $\mathrm{BD}$ of the literature. The characteristic of $\mathrm{BD}$ lies in the mining of big data, but it must rely on the distributed processing of CC, distributed databases, cloud storage and virtualization technologies. BD is just a representation or characteristic of the current stage of the development of the Internet. Against the backdrop of the technological innovation scene represented by CC, these data, which were originally difficult to collect and use, are beginning to be easily utilized through various industries [7]. With continuous innovation, $\mathrm{BD}$ will gradually create more value for mankind.

In the digital age, the data processing of university libraries is mainly to digitize and network literature materials, and its purpose is to realize the full use of academic data by teachers and students. With the development of informatization and digitization, the current library is constantly changing the traditional service mode, and the large-scale use of new information equipment, especially the increasing proportion of digital resources in the entire resource procurement, makes the library gradually change from the document resource center to the data center [7]. The integration of digital resources in the library coincides with the widely promoted applications of $\mathrm{BD}$ in libraries. The construction of the library's digital resources also needs to be established under the current environmental conditions of big data, with corresponding adjustments and construction in accordance with local conditions, so that limited resources can be maximized. In the EBD, the analysis and processing of massive literature data will become the new trend of ULA. Its service focus will gradually shift from traditional business to data mining. Therefore, in the EBD, the ULA should strengthen the depth of resource organization and processing in terms of resource construction. In terms of technical application, strengthen the application of clustering technology, and widely use data analysis technology. At the same time, focusing on the intelligence of data mining is an inevitable trend in the development of ULA. With the continuous development of AI, the intelligent level of processing BD by the ULA will be higher and higher. Faced with massive digital network information resources, traditional resource search, analysis, screening, and integration technologies can no longer satisfy the needs of modern people.AI can quickly and intelligently search among the global massive digital information resources, Intelligent analysis that, intelligent screening, in the future, relying on AI, the ULA can better understand readers' professional and personalized literature needs through $\mathrm{BD}$ mining.

In the $\mathrm{BD}$ environment, it is oriented to user needs and relying on $\mathrm{BD}$ technology. On the basis of maintaining the existing development advantages, it is 
necessary to rely on the existing service platform, innovate the service model, and establish a management mechanism and service system based on big data [4]. In the EBD, another type of ULA- "virtual alliance (VA)" will become the protagonist. "Incorporeal alliance" does not mean that there is no entity participating in the alliance, but that the main feature of this type of alliance is reflected in its incorporeal part. Relying on the "digital library" (DL) to establish a LA is very close to the "incorporeal alliance", and even closer is the "cloud library" (CL). The CL is an upgrade of the "DL". If the ULA adopted the CL as the main method when it was formed, plus the two technologies of "BD processing" and AI, it can be said that it has entered the "VA" stage. The technical basis of the CL is CC. The means are resource integration and efficient matching of supply and demand. The purpose is to improve resource utilization and service efficiency [8]. The "virtual body alliance" is an important direction for the development of the ULA in the future, and its essence is a "cloud" platform with BD processing $\mathrm{AI}$ and other technologies as the core [9].

In the VA era, the ULA Based on CL can solve the problem of deep resource sharing, but it is not enough to rely on cloud books to break the information island phenomenon of each university library. Under the condition of modern information technology, it is another goal for us to realize the free communication of registered readers between the union libraries. Due to the application of face recognition and other technologies, it has solved the technical problems of personnel exchanges, making it possible for readers to freely shuttle between university libraries and borrow their favorite books and materials. Therefore, the construction of SL is also the due meaning of the development of University Library Alliance in the future [10]. With the support of cloud computing and AI technology, the free flow of personnel, the deep sharing of electronic resources, and the free mutual borrowing of paper books become possible. This not only helps to improve the efficiency of literature resources utilization among university libraries, avoid the idle and waste of resources, but also helps to improve the management and service efficiency of each library. In terms of technology, the commercialization of CC and AI technologies has become more and more mature. As long as the top-level design and strategic planning are well completed, it is not a problem to apply CC and AI technologies to the construction of the alliance.

\section{Conclusion}

In fact, the above three types also represent the three stages of the development of ULA in China. In the era of HA, we have completed three aspects of work: first, we have basically realized the digitization of literature resources; second, having built a sharing platform of literature resources; third, having realized the interconnection between member libraries. It can be said that the resource construction of UL has gone through the stage of digitalization and networking, and the HA formed on this basis has also fulfilled its historical mission well. Now, it 
is a new stage of transformation and upgrading of the ULA construction. The intelligence of cloud service and BD processing is the sign of the coming era of "virtual body alliance" of the UL. With the more and more specialized and personalized literature demand of readers, how to use BD mining, AI and other technologies to meet the needs of readers is an important issue facing the ULA. The reason why CC and AI technology will become the main technical support of VA lies in that they can break the information isolated island phenomenon between Chinese university libraries, and then completely break the barriers of document information resource sharing, and provide the greatest convenience for the free exchange of personnel and information, so as to truly achieve the reader centered. From the service point of view, we should make the readers as the center, not the literature resources as the center, so that the construction and sharing of the literature resources are completely around the readers, which is the direction of the construction of the ULA in the future. Only by using AI and CC technologies, the construction of the CULA can enter into the realm of freedom. Of course, although we are full of expectations for the use of technologies such as CC and AI to build VA, further research is needed for specific technical routes, construction concepts, and strategic planning.

\section{Conflicts of Interest}

The author declares no conflicts of interest regarding the publication of this paper.

\section{References}

[1] Yi, L. (2014) Consideration on the Development of China's University Library Regional Consortiums: A Case of BALIS. Library Work in Colleges and Universities, No. 3, 53-55.

[2] Pei, X.F. (2004) Study on Consortium Development of University Library. Library Work and Study, No. 2, 5-7.

[3] Wang, Y. and Shao, B. (2020) The Status Quo of the Development of Digital Library Federation in Domestic Universities: Insufficient Connotation and Structural Remodeling. Researches in Library Science, No. 4, 87-93.

[4] Chen, X.Z. and He, Y.T. (2018) Research on the Construction and Development Strategies of Regional Library Alliance under the Background of Big Data: Taking Jiangxi Academic Library Alliance as an Example. New Century Library, No. 11, 80-83.

[5] Zhou, J., et al. (2007) The Cooperation Practice and Development Research of Beijing University Library Comorlium. Library and Information Service, No. 3, 121-124.

[6] Yi, L., et al. (2017) How to Construct the Beijing-Tianjin-Hebei University Library Consortium under the Background of Regional Integration. Library Journal of Henan, No. 3, 63-64.

[7] Liu, H. (2015) Construction on Digital Resources Alliance in the Circumstance of Big Data. Library Work in Colleges and Universities, No. 3, 46-50.

[8] Kang, S.B. (2020) Comparative Study on Operation Modes of Shared Cloud Libraries: Taking 123 Library and Jieshuren as Examples. Library Theory and Practice, 
No. 3, 123-128.

[9] Lin, X.X. (2019) The Mechanism and Content of Reading Promotion and Intelligent Service Innovation Based on "Cloud Library+". Library Theory and Practice, No. 6, 29-37.

[10] He, D. (2020) A Strategy of Smart Library Construction in the Future. Journal of Service Science and Management, 13, 330-335.

https://doi.org/10.4236/jssm.2020.132021 